\title{
Sexo y Pobreza
}

\author{
ENsayo sobre la poesía de Pablo Neruda
}

Es fuerte y joven. $\mathrm{L}_{a}$ llamarada ardiente del sexo corre por sus arterias en sacudimientos eléctricos. El goce ya ha sido descu. bierto y lo atrae como la cosa más simple y maravillosa que le hubieran mostrado. Antes le enseñaban a esconder la inmundicia del bajo vientre y su frente de niño se arrugó en una interroga. ción inconsciente. Después el primer amigo le reveló el secreto. $\mathrm{Y}$ el placer solitario fue corrompiendo la pureza del alma y abrién. dole goces desconocidos hasta entonces. Pero ya pasó el tiempo aquél. Ahora, fuerte y joven, busca un objeto en quién vaciar su copa de salud. Es el animal que busca sencillamente una salida a su potencia natural. Es un animal macho y la vida debe darle la hembra en quien se complete, aumentándose.

Por eso busca. La hermana ha crecido como él; como él es fuerte y poderosa; la juventud hízole ya las ánforas del pecho y los ojos que guardan el deseo. Pero es su hermana. $Y$ aún hay castigo para el amor entre ambos.

Pero hay más mujeres. Las calles llevan cientos de hembras inquietas y vigorosas y el hombre busca de nuevo. Pero descubre que la entrega de una de esas mujeres trae una cosa divertida y rara: la "deshonra" de la que quiso, como él, gozando un placer para el que la naturaleza le dio un órgano.

Entonces el hombre joven, que es honrado, aprende a conocer la maldad hipócrita que inventaron para impedir la eclosión plena de sus inclinaciones físicas. Pero siempre busca. $Y$ hay la casa de placer. Pero el hombre que es puro, reduce su necesidad na. tural y desprecia, compadeciendo, la máquina que ha de darle el placer a tanto la hora.

$\mathrm{Y}$ entonces el hombre joven y fuerte siente una oleada de 
rabia contra los estúpidos que hicieron el marco cuadrado y tieso en que debe meter su vida. Desprecia y odia la ley que le va dando en la cara un latigazo por cada tentativa de su ser hacia lo que todos hacen como larvas oscuras en los rincones ocultos y siente deseos de volver su rabia sobre los que le dieron el deseo ancestral que lo amarra como un gancho enorme a la vida. $Y$ deja de ser puro y quiere comprar amor.

Pero es pobre. $\mathrm{Y}$ piensa que el placer y todo lo que han hecho sobre la tierra, con la tierra misma, es para los que todo lo tienen y lo obligan a él, fardo de deseos naturales, a ser un mueble pegado al oro de los otros. ${ }^{1}$

Esta página, escrita por Neruda a los 17 años, es suficientemente demostrativa de que su poesía amorosa no es una pura invención literaria. Surgidos de concretas condiciones de existencia, libros como $E l$ bondero entusiasta y los Veinte poemas de amor reflejan la situación social del poeta, su gris y oscura pobreza.

Poesía amorosa hay ya en Crepusculario. No es lo fundamental, sin embargo. Como antecedentes significativos, vale la pena recordar Farewell, que proyecta su historia sentimental sobre los Veinte poemas, Nada me bas dado.. y Morend, la besadora. Esta última composición presenta un pequeño y singular enigma. ¿Ha reparado el lector en que esa morena del título se contradice flagrantemente con el inicio del poema: cabellera rubia...? Se trata, con toda evidencia, de una paradoja poética sobre la figura femenina, en que las variedades rubia y morena pretenden ser identificadas, fusionadas casi, en un único ejemplar de mujer. Detrás de este intento, hay algunos modestos precedentes líricos, especialmente en Pedro Antonio González, Carlos Pezoa Véliz, José Domingo Gómez Rojas y Romeo Murga. Todos ellos han concebido los distintos retratos femeninos como entidades contrapuestas, que oscilan a menudo entre la sensual y la mujer ideal. A Pezoa Véliz pertenecen dos sonetos encabezados con el título genérico de Cuerdas beridas. ${ }^{2} \mathrm{~A}$ una rubia es metamorfosis de la virgen cristiana, que representa el plano ideal de la belleza, el ensueño y la aspiración lejana; $A$ una morena, en cambio, señala el costado ardiente del amor, el llamado sensual de la hembra. En cuanto a José D. Gómez R., tiene en su adolescente poemario Rebeldías líricas (1913) un pequeño ciclo denominado "El

1 Claridad, 2 de julio de 1921.

2 Raúl Silva Castro: Carlos Pezoa Véliz (1879-1908), cit., p. 202. Los poemas están fechados en 1900. 
perfume de las musas", tal vez inspirado en "El año lírico" de Rubén Darío. En él incluye a las musas de las cuatro estaciones. La musa primaveral aparece vista en términos semejantes a la virgen rubia de Pezoa Véliz, mientras la estival es la musa morena, la Musa-Placer. Y sobre Romeo Murga escribe uno de los mejores conocedores de este ol. vidado poeta: "Dignos de nombrarse son dos poemas, 'La niña rubia' y 'Morena', ambos realizados con un sabio tratamiento técnico. 'La niña rubia' está escrita en octosílabos que acentúan la claridad cromática, la impresión de levedad que requiere el tema. (...) Este poema, bañado de luz, contrasta con el tono grave y nocturno de 'Morena'..."3 En el caso de Neruda, esta 'morena rubia' de Crepusculdrio prepara el segundo de los Veinte poemas y luego, ampliado a escala cósmica, la gran arquitectura de Residencia en la tierra, en que el juego de complemen. tarios se funde con el prodigioso despliegue del devenir natural. Por eso es profundamente verídica esta declaración posterior de Neruda: "Siempre me han preguntado cuál es la mujer de los Veinte poemas, pregunta difícil de contestar. Las dos o tres que se entrelazan en esta melancólica y ardiente poesía corresponden, digamos, a Marisol y Marisombra. Marisol es el idilio de la provincia encantada, con inmensas estrellas nocturnas y ojos oscuros como el cielo mojado de Temuco. Ella figura con su alegría y su vivaz belleza en casi todas las páginas, rodeada por las aguas del puerto y por la media luna sobre las montañas. Marisombra es la estudiante de la capital. Boina gris, ojos suavísimos, el constante olor a madreselva del errante amor estudiantil. El sosiego físico de Jos apasionados encuentros en los escondrijos de la urbe." 4 A decir verdad, si juntamos la anécdota de Farewell, esa complementariedad postulada en Morena, la besadora y la común inmersión de poeta y mujer dentro de la desbordante realidad en el poema Nada me bas dado..., tendremos un haz de coordenadas que regirá la poesía de los Veinte poemas de amor y una canción desesperada.

La poesía de Neruda tiene tal persuasión emocional que es fácil olvidar sus motivaciones inmediatas. Los Veinte poemas fueron para la generación coetánea de Neruda y siguen siendo para las nuevas juven. tudes un breviario de amor, un manual de enamoramiento. Constituyó este Jibro, a su manera, una especie de "estilo nuevo" que se expandió con singular fortuna a través de los países hispanoamericanos. Hay un síntoma externo y material de esta proyección: es la obra de Neruda

3 Jorge Teillier: "Romeo Murga, poeta adolescente". Atenea, núm. 395, eneromarzo de 1962, pp. 166-7.

${ }^{4}$ Memorias: 'O Cruzeiro Internacional'. 
que más reediciones lleva y que con más traducciones a otras lenguas cuenta. ${ }^{5}$ Como toda gran lírica de amor, la de Neruda ha logrado crear y expresar una sensibilidad desconocida en ese orden de las relaciones afectivas. En ninguna parte más que en esta clase de formaciones literarias son más palpables e invisibles a la vez las condiciones históricosociales que constituyen su base objetiva. En general, un intento meto. dológico de este tipo se complica por el carácter de eternidad con que, según nuestra perspectiva temporalmente limitada, aparece revestido el sentimiento amoroso. $\mathrm{L}_{\mathrm{a}}$ idea de una disposición humana inmutable, la capacidad de amar, entra aquí en pugna con las variaciones históricas y culturales que tratan de imponerse. De hecho, no sería imposible realizar el proyecto de Baudelaire de escribir una historia del erotismo que mostrara el carácter de producciones humanas específicas, culturalmente diferenciadas, de la emoción y del acto amatorios. Es también el anhelo, más recientemente formulado, del historiador francés Lucien Febvre. ${ }^{6}$ Pues es una honda historicidad la que manifiestan las expre. siones poéticas más egregias del sentimiento amoroso.

El bíblico Cantar de los cantares con su lujuria rústica y exquisita, acoplada a las alegorias misteriosas de la Thora; las Anacreónticas y su juego hedonista que reflejan el refinamiento del mundo alejandrino; las Elegias de Propercio, que despliegan ante nosotros, en sus detalles y en su picardía, la técnica de seducción y las modalidades del eros im. perial; la poesía trovadoresca, con su alta culminación en la Vita nuova, donde se da vida al sentimiento filosófico medieval de la mujer; Petrarca y el Canzoniere, que comienzan a encarnar la imagen renacentista de la feminidad; el sentimiento enlutado del amor que trae el romanticismo desde las Méditations poétiques adelante, son sólo unos pocos hitos memorables en el desarrollo del género amoroso.

La omisión del marco social en que se inserta esa poesía de Neruda hace posible que se sostengan posiciones completamente antagónicas en cuanto a la naturaleza de su figura femenina. Para Mario Rodríguez, crítico chileno, la mujer de los Veinte poemas es una mujer plenamente carnal, objeto sensual ante todo, junto con ser encarnación privilegiada de la tierra y de la vida. Para el crítico francés Alain Sicard, en cam. bio, lo que en ella predomina es su aspecto ideal; lejos de ser una musa

5 En la bibliografía preparada por Hernán Loyola, el libro en cuestión figura con 37 ediciones (chilenas, argentinas y una mexicana). Lo cual representa, en promedio, apenas un poco menos de una edición anual desde 1924 hasta 1968. La aceptación tan sostenida en esta poesía es, entonces, un hecho sociológico y cultural que es necesario explicar.

6 "No tenemos historia del Amor, ipiénsese en esto!" Cf. El problema de la incredulidad en el siglo XVI. México, Uteha, 1959, p. XII, nota 45. 
de carne $y$ hueso, es más bien una imagen de ensueño, la proyección de su fantasía poética. ¿Será posible, entonces, hacer compatibles afirmaciones $\tan$ opuestas, que nos llevan a concebir la mujer nerudiana de modo tan fluyente y contradictorio como esa "morena rubia" de Crepusculario?

Para situar el problema en su raíz, es necesario describir las formas concretas de relación amorosa que se poetizan en los Veinte poemas. Ellas pueden reducirse a tres clases, según que se trate de la mujer interior, la enamorada juvenil o la hembra objeto de goce sexual.

a) La mujer interior. Es pura imagen subjetiva, espejismo creado por las fuerzas del deseo y de la fantasía conjuntamente. La vemos diseñada con claridad en un hermoso y discutido poema que es paráfrasis de otro de Tagore:

En mi cielo al crepúsculo eres como una nube y tu color y forma son como yo los quiero. Eres mía, eres mía, mujer de labios dulces, $y$ viven en tu vida mis infinitos sueños.

Proyección de los sueños, esta mujer sólo existe en el escenario íntimo del poeta. Fantasma del crepúsculo, es otra transfiguración suya, en medio de una atmósfera en que la interioridad se impregna de atardeceres luminosos. He aquí, por lo tanto, la paradoja inquietante de este ser:

Oh segadora de mi canción de atardecer, cómo te sienten mía mis sueños solitarios!

Eres mías, eres mía, voy gritando en la brisa de la tarde, y el viento arrastra mi voz viuda.

"Mía" y ausente a la vez, esta mujer tiene la ausencia de la muerte; el poeta que la ama y la hace suya es solitario y viudo. Se hace patente, así, la intensa fugacidad de este ensueño interior.

Cazadora del fondo de los ojos, tu robo estanca como el agua tu mirada nocturna.

Tocamos ahora el secreto material de esta mujer, el ámbito de su aparición. Lo dice el poeta claramente. Ella surge "en el fondo de los ojos". Dirigidos éstos constantemente hacia los cielos exteriores, se vuel. 
ven ahora hacia la profundidad del sujeto, donde cavan esta imagen hecha de puros efluvios.

En la red de mi música estás presa, amor mío, y mis redes de música son anchas como el cielo.

Mi alma nace a la orilla de tus ojos de luto.

En tus ojos de luto comienza el país del sueño.

Aquí se consolida, es decir, se hace más ingrávida y sutil que nunca la visión de esta mujer, suma de emanaciones sin soporte material: la mirada sin los ojos, la dulzura de los labios sin su carne, música sin aire y $\sin$ instrumentos. De ahí que la música exprese sobre todo la fulguración de esta mujer, fuego fatuo nacido y desvanecido en la intimidad del sujeto. El abrazo sólo atrapa su muerte. Por eso hay en este poema un desenlace de duelo, que fija para siempre a esta mujer como la musa muerta por excelencia, la musa difunta del alma.

Detrás de esta configuración está la visión modernista de la mujer, que a su vez procede del sentimiento amoroso romántico. Aparte del caso más destacado de Dario, en Chile cultivan esta imagen Manuel Magallanes Moure y Angel Cruchaga. La experiencia que el primero poetizó está resumida con exactitud en este verso de $E l$ bondero entusiasta:

Eres lo que está dentro de mí y está lejano.

En el mismo sentimiento se detiene Angel Cruchaga en su hermoso libro Las manos juntas (1915), formulándolo conscientemente en una prosa poética contemporánea, Mujeres lejanas. ${ }^{\top}$ En otro texto escribe, dando cuenta igualmente de la situación que describimos: "En el silen. cio hermético y prolongado, se contempla la imagen de nuestro yo, al principio indefinida como un presentimiento, después esbelta, fuerte y segura."8

Lo que Manuel Magallanes y Angel Cruchaga actualizan en la lírica chilena, como jalones pre-nerudianos de esa experiencia, en realidad es un fenómeno más amplio y sostenido. Así como el yo ha sido el pronombre de la autoconciencia filosófica, la autoconciencia lírica encuentra su formulación en el posesivo mia. Mía es el cogito poético modernista, por lo menos desde las obras más decisivas de Rubén Darío.

7 Cf. Jaime Concha: "Muerte y canto en Angel Cruchaga". Estudias Filolot. gicos, 4, 1968, p. 139.

8 Ibid. 
En el centro de Prosas profanas hallamos meditadas las relaciones entre el sexo y el ensueño en el par de poemas Mía y Dice Mía... ${ }^{\circ}$ De ahí que estas fórmulas haya que valorarlas, también en el caso de Neruda, sobre el trasfondo de esa tradición.

En El bondero entusiasta hay un fragmento donde lo que exponemos se despliega con insuperable claridad. Es el fragmento 7, del cual copiamos algunos momentos relevantes:

Alma mía! Alma mía! Raíz de mi sed viajera, gota de luz que espanta los asaltos del mundo.

Flor mía, Flor de mi alma, Terreno de mis besos.

Canción, sueño, destino. Flor mía, flor de mi alma.

Aletazo de sueño, mariposa, crepúsculo.

Eres. Entonces, eres, y te buscaba entonces.

Eres labios de beso, fruta de sueños, todo.

Los dos brazos que surgen como juncos de asombro.

Todo tu cuerpo ardido de blancura en el vientre.

Las piernas perezosas. Las rodillas. Los hombros.

La cabellera de alas negras que van volando.

Las arañas oscuras del pubis en reposo

Se trata, como es evidente, de una verdadera deducción idealista de la mujer, que plasma su corporeidad a partir de puros datos interiores. Desde la extrema blancura del alma el poeta desprende, mediante flexibles modulaciones del deseo, la sombra en reposo, sexuada, de ella. De lo difuso a lo nítido, todo su esfuerzo se define por una búsqueda de contornos, en los que trata de apresar la imagen vagabunda así nacida:

Te parió mi nostalgia, mi sed, mi ansia, mi espanto.

$Y$ ya lo vemos: esta ansia inaprehensible se prolonga en la caricia, única capaz de dar tangibilidad al cuerpo soñado:

La delgada caricia que te hace arder entera.

Es fácil advertir, entonces, que los tres tipos de mujer mencionados no

\footnotetext{
9 En lo substancial, esta secuencia entre el sexo y el espítitu se recoge en Morena, la besadora: "huella que dura en el lecho, / huella que dura en el alma, / palabras locas."
} 
serán formas irreductibles; habrá, como veremos con más detalle a continuación, cruces, superposiciones, tránsito de una a otra. Con más precisión: esos tres modos de lo femenino serán sólo grados en un mismo camino de constitución de la objetividad.

b) La enamorada juvenil. Es el objeto de sus encuentros en la ciudad, dentro del marco de su vida estudiantil. El poeta reitera algunas pálidas señas de su existencia: los ojos, las manos, la voz, su boina gris. Desnudos decentes, en primer lugar, que forjan un esbozo inicial de corporeidad, sobrepasando ya la irrealidad de la figura anterior; voz en que encarna, en segundo lugar, esa música inaccesible de su interioridad; finalmente, un detalle vestimentario que remite a un uso social, a una moda juvenil de la época. Sin embargo, tampoco la tangibilidad de esta mujer es completa. Su relativización se produce especialmente por la atmósfera de recuerdos que la rodea:

Te recuerdo como eras en el último otoño.

Eras la boina gris y el corazón en calma.

En tus ojos peleaban las llamas del crepúsculo.

$Y$ las hojas caían en el agua de tu alma.

Siempre evocada, la figura de la joven se adelgaza tras el velo del tiempo. Es otra forma de la ausencia, una ausencia que crea también un tembloroso vacío en torno a esta enamorada estudiantil. Distante, lejana, a esta amada se la anhela desde otro punto del espacio, lo que acerca su figura a la materialidad transparente de la primera forma de femineidad:

Cielo desde un navío. Campo desde los cerros.

Tu recuerdo es de luz, de humo, de estanque en calma!

Más allá de tus ojos ardían los crepúsculos.

Hojas secas de otoño giraban en tu alma.

Estamos ante una segunda forma de la ausencia, no la definitiva de la muerte, aunque sí la de una lejanía temporal y espacial a la vez, que parece resumirse en el clima cambiante de las estaciones estudiantiles: el otoño universitario y el verano en la provincia.

Otras veces la estudiante es presentida, esperada con ansia. El fracaso del anhelo intensifica esta sensación de ausencia, extremándola hasta tocar el grado de lo irrecuperable. Es el momento perdido, el momento del amor que no nació. Desde este lado, esta nueva ausencia se avecina, asemejándose a su primera manifestación: 
Hemos perdido aun este crepúsculo.

Nadie nos vio esta tarde con las manos unidas

mientras la noche azul caía sobre el mundo.

Entonces, dónde estabas?

Entre qué gentes?

Diciendo qué palabras?

Por qué se me vendrá todo el amor de golpe

cuando me siento triste $y$ te siento lejana?

Esta amada estudiantil no llega nunca: es sólo el objeto de un recuerdo, la evidencia de su irremediable lejanía.

c) La mujer poseida. Todo lector de los Veinte poemas recuerda el inicio del libro, el notable primer poema en que la experiencia sexual alcanza una reproducción lírica exactísima, casi literal. El poema tiene la misma procesalidad del acto amoroso, desde la absorción contemplativa hasta el desenlace orgástico. Cuerpo de mujer... comienza el sujeto, recorriendo las palpitantes suavidades de la forma femenina, con caricias que constituyen la unión de lo visual y de lo activo, la operación aliada de los ojos y del tacto; cuerpo de mujer mí... finaliza, adquiriendo el posesivo toda su significación real. La cima de la actividad erótica está descrita, en primer lugar, en términos veristas:

Ah los vasos del pecho! Ah los ojos de ausencia!

Ah las rosas del pubis! Ah tu voz lenta y triste!

Pero esos "ojos de ausencia", esa "voz lenta y triste" se asocian también en su poesía con los rasgos de la mujer irreal. Detalles evidentes del orgasmo femenino, son también puentes poéticos para una irrealización de la mujer carnal, para despotenciar a esta forma femenina de su certidumbre sensible en beneficio de una inclaudicable certeza interior. Hay, por lo tanto, una tercera forma de ausencia, que no corresponde únicamente a esta nueva mujer, sino que se hace delgada capa entre la amada estudiantil y la hembra del primer poema. Es el silencio. En el poema por antonomasia de la mujer silenciosa, el Poema 15, se enumeran con gran fidelidad estas formas reconocibles de la ausencia:

Me gustas cuando callas porque estás como ausente.

Distante y dolorosa como si hubieras muerto. 
Silencio, distancia, muerte: tres grados de una misma ausencia imperante en esta poesía.

En realidad, lo que unifica estas tres variedades de la amada es el vínculo concreto del Deseo. La subjetividad se define en esta poesía por su más primatio conato de autoconciencia, la búsqueda anhelosa de algo de lo cual se depende pero cuya posesión es mortal para esa misma búsqueda. El objeto y su ausencia son correlativos con este movimiento. de las fuerzas interiores. Energía sin satisfacción posible, el deseo es llamado, apelación sin término. "Ansia sin límites", "dolor infinito", así se nombra al deseo en esta poesía. "Sed", "ansia", "nostalgia" son expresiones que se reiteran en $E l$ bondero entusiasta y en los Veinte poemas. $\mathrm{No}_{\mathrm{hay}}{ }_{2}$ en consecuencia, ni mujer ideal ni mujer carnal en estos libros nerudianos: sólo formas distintas forjadas por la realidad básica del deseo, vicisitudes suyas.

Neruda describe antes que nada la repercusión interna de esa experiencia, los efectos sufridos por él mismo:

Ternura de dolor, y dolor de imposible, ala de Ios terribles deseos, que se mueve en la noche de mi carne y la suya con una aguda fuerza de flechas en el cielo.

Algo de inmensa huída, que no se va, que araña adentro, algo que en las palabras cava tremendos pozos, algo que contra todo se estrella, contra todo, como los prisioneros contra los calabozos!

Luego, la ansiosa proyección a la exterioridad:

Ella, tallada en el corazón de la noche, por la inquietud de mis ojos alucinados: ella, grabada en los maderos del bosque por los cuchillos de mis manos, ella, su goce junto al mío, ella, sus ojos enlutados, ella, su cotazón, mariposa sangrienta que con sus dos antenas de instinto me ha tocado!

Hallamos, una vez más, la gradual progresión hacia la corporeidad. Primero, la irrealidad puramente imaginaria a través de los ojos; segundo, 
la irrealidad materializada que las manos modelan. Las transiciones son imperceptibles. Los ojos tallan, tienen ya una incipiente manualidad, producto del magnetismo que la exterioridad ejerce sobre ellos. Las manos comienzan a perder la blanca pasividad estudiantil, aunque todavía no alcanzan su posterior disposición guerrera. Incisivas, estas manos tratan de grabar una imagen; activas, ellas sólo prolongan el ensueño. El poeta trabaja su interioridad. Como esos versos que Neruda escribía en su infancia sobre tablas cualesquiera, esta mujer es una inscripción. He aquí, en esquema aristotélico, esta extraña operación: sobre las materias de su niñez, con una eficiencia entre real e impracticable, el poeta se complace en depositar las formas de su invención. Es, ciertamente, bien desconcertante esta metamorfosis del poeta: sus ojos quieren volverse dedos, quieren tocar, y aun modificar, las cosas exteriores; sus manos se ejercen hacia adentro, pretenden esculpir fugitivos personajes de su intimidad. "Con ojos que palpan y con manos videntes": el desiderátum goetheano de las Elegías romanas es, en Neruda, un conflicto, que determina que su noción de la manualidad progrese, sin duda. Aunque algo de ello conserva todavía, esta actividad que vemos en El hondero entusiasta no es ocio estético exclusivamente. Entre el instrumento musical -ese violín de Crepusculario- y los instrumentos guerreros de Residencia en la tierra, hay esta forma intermedia, punzante y doméstica a la vez, útil y lúdica. Ocio y arte que no se diluye en melodía, que enfrenta ya a una materia resistente, éste del grabado se aproxima insensiblemente al para. digma infantil del trabajo.

Es claro, además, en estos versos: mujer-hembra, mujer difunta, lo único básico es el dato primario del instinto, las fuerzas inconscientes del deseo, del cual ojos y manos son sólo tentáculos vehementes. De hecho, todo El hondero entusiasta se explica a través de esta dialéctica del deseo. Su itineratio es el de una subjetividad pugnaz, que busca romper los limites individuales, en pos de una comunicación con la mujer. Desde la mujer-alma del comienzo hasta la "canción del macho y de la hembra", su recorrido no es otro que el de la materialización del objeto amoroso. Una vez más lo decimos: la mujer nerudiana no puede pensarse como figura estática, dada para siempre a la visión del poeta, sino como imagen en curso de constitución. Se comprende, entonces, el papel fundamental que cumple la experiencia amorosa en la totalidad de la poesía nerudiana. En La sagrada familia, refutando las especulaciones de los neo-hegelianos, escriben Marx y Engels: "...en el amor, que más que ninguna otra cosa, enseña al hombre a creer en el mundo material (gegenständliche Welt ausser ibm) y que no sólo hace del hombre un 
objeto, sino también del objeto un ser humano."10 $\mathrm{Y}$ más adelante: "Lo que la crítica ataca aquí no es solamente el amor, es todo lo viviente, todo lo inmediato, toda experiencia sensible, en suma, toda experiencia real (alle wirkliche Erfabrung überbaupt), de la que no se sabe de antemano el 'de dónde' ni el 'a dónde' ". ${ }^{11}$ Al final de El bondero entusiasta, abolido ya el sujeto individual, emerge una sola substancia solidaria:

Y tú, en tu carne encierras

las pupilas sedientas con que miraré cuando

estos ojos que tengo se me llenen de tierra

Es la primera extinción de los ojos estudiantiles. Pese al socorrido tópico, la imagen adquiere relieve dentro de la legalidad del poema. Se apagan esos ojos que extraían su luz de las bellezas del cielo, se oscurece su alto abolengo espiritual. Este poeta "solo, como el primer muerto" en su empecinada individualidad, se prolonga en la otra mitad necesaria del juego amoroso. El privilegio de los ojos ha dejado de ser un atributo singular: es una llama comunicable, un derecho compartido. Esta conclu. sión en la tierra de una experiencia en que "el hondero" manifestaba su vocación por las alturas no es un azar. Es el modo macabrista de un descubrimiento que en Tentativa del bombre infinito va a ser contacto físico (:"Araño esta corteza destrozo los ramales de la hierba") y que en Residencia en la tierra será afanosa averiguación geológica. En otra parte, en el Poema 17, Neruda expresa maravillosamente bien lo que los textos filosóficos postulan conceptualmente:

Tú, mujer, que eras alli, qué raya, qué varilla de ese abanico inmenso? Estabas lejos como ahora. Incendio en el bosque? Arde en cruces azules. Arde, arde, llamea, chispea en árboles de luz.

Se derrumba, crepita. Incendio, incendio. Y mi alma baila herida de virutas de fuego. Quién llama? Qué silencio poblado de ecos?

Es el llamado de la ausencia, la atracción de la realidad exterior que experimenta un sujeto que se ha complacido largamente en el seno de su hermetismo. Porque la ausencia permanente de la mujer en esta poesía es esto, en su contradictoria textura: "silencio poblado de ecos", "dis-

10 Marx-Engels: Die beilige Familie, cit., p. 21.

11 Ibid., p. 23. 
tancia" poblada de contactos, "muerte" poblada de vida. Sin existir, la mujer tiene una presencia poderosa en el cauce del deseo. Incompleto, el poeta sabe que sin su participación en ella queda huérfano de toda realidad. Justamente de esa realidad que en su primera manifestación es llama, fuego, incendio. Estamos aquí, de nuevo, frente al contacto original del poeta con las cosas exteriores. Ya recalcábamos este pasaje: "Tal vez el recuerdo más remoto de mi propia persona es verme sentado sobre unas mantas frente a nuestra casa que ardía por segunda o por tercera vez." El amor renueva, en la forma ardiente del deseo, esa imagen del fuego perpetuamente encendida en su poesía. Hay siempre, en estos libros amorosos de Neruda, configuraciones intermedias cuycs extremos inicial y final pueden descubrirse en Crepusculario y Residencia en la tierra. De igual modo como ocurre con la secuencia de instrumen. tos que describimos, tenemos ahora la siguiente serie: una casa quemada en la niñez, ardor crepitante del cuerpo, cenizas históricas de la Conquista. Desde el origen memorable de la subjetividad hasta la memoria colectiva que aportan las Residencias, el sonido del fuego con sus armónicos (chispas, cenizas, virutas, humo, etc.) crece por una suerte de intususcepción, devorando la eternidad del alma en el tiempo quemante de la materia. En este cuerpo que se incendia a sí mismo de sed y de deseo ya no cabe la música del alma, esa oquedad independiente de toda experiencia:

Hé aquí mi sed que aúlla sobre mi voz ya muerta.

Hé aquí mi voz caída. Hé aquí mi alma caída.

Caen sobre mis ruinas las vigas de mi alma.

Ya no podría escribir Neruda, luego del deseo y del acto amatorios, estas palabras de El licor singular: "Nunca pude arrojar mi alma de mi lado, confundirla, mezclarla. Viajó y viaja aún, silenciosa, tal un barco pescador entre la bruma, por las almas extranjeras que se abrian o cerraban para recibirla o rechazarla. Pero siempre, liberada de la hospitalidad o del rechazo, te volvía a encontrar, alma mía, incontaminada, siempre mejor y siempre igual." 12 El barco de la infancia, el paisaje irisado del alma no sobreviven, no pueden sobrevivir a la imperiosa apetencia material contenida en el sexo. Síntesis precursora de dos experiencias de distinta amplitud, esta visión del incendio amoroso condensa reminiscencias infantiles o impresiones concretas (incendios de bosque), extendiéndolas hasta abarcar las dimensiones de un territorio, de un suelo indispensable

12 Claridad, 22 de julio de 1922. 
para el surgimiento de los contenidos históricos. Brota, entonces, la imagen del deseo como marea, como caricia del mar en el flanco de la costa:

He visto tendido frente a los mares del Sur, arrollarse las aguas y extenderse inconteniblemente, fatalmente en las mañanas y en el atardecer.

Agua de las resacas sobre las viejas huellas, sobre los viejos rastros, sobre las viejas cosas, agua de las resacas que desde las estrellas se abre como una inmensa rosa, agua que va avanzando sobre las playas como una mano atrevida debajo de una ropa, agua internándose en los acantilados, agua estrellándose en las rocas, agua implacable como los vengadores y como los asesinos silenciosa, agua de las noches siniestras debajo de los muebles, como una vena rota, como el corazón del mar en una irradicación temblorosa y monstruosa.

Incendio de los bosques o aguas marinas, la energía del deseo va delimitando un campo que coincide con la geografía de la infancia. El amor no conduce, por lo tanto, en este poeta, a una objetividad abstracta, a una realidad a secas, sino a un ámbito particular, al objeto amable de su experiencia más entrañada. La Frontera y las costas de su región reaparecen una vez más perdiendo su primera inmediatez y determinando un balbuceante nivel de conciencia. Es realmente sobrecogedor el modo en que el poeta se introduce en intuiciones que para él han de ser definitivas. Esas "viejas huellas", esos "viejos rostros", esas "viejas cosas", pronunciadas con un énfasis obsesivo, ¿qué son sino oscuros presentimientos de algo cuyo sentido aún no se comprende? Conocimientos sin reconocimiento, como diría Hegel. Porque lo mismo que los "cascos enemigos" que Neruda sorprendía en una faena de trilla serán anticipación del advenimiento de los animales de la Conquista, señales premonitorias de la herradura, estas huellas de $E l$ bondero entusitsta las volveremos a encontrar, con idéntica ambientación, en $E l$ sur del acéano, donde ya exhibirán un semblante preciso: la pisada de los caballos, los rastros de la marcha conquistadora. 
A esta altura es posible desprender algunas conclusiones generales. En primer término, el deseo de donde irradia la población femenina de esta poesía se nos presenta con una peculiar estructura. Es, digámoslo ya, una modalidad de acción, la acción ejercida contra sí mismo. En otras palabras, una acción inútil. El poeta lo dice con extrema claridad:

De mi pelea contra mí mismo, fuiste.

Es decir, el deseo es trabajo sobre la propia subjetividad, una labor que modela los contornos del sujeto, que va palpando sus vacíos y sus movimientos. Alianza de sufrimiento y de trabajo, el deseo es sufrimiento sin pasividad, sufrimiento activo y es trabajo sin materia física sobre la cual ejercerse, trabajo inmaterial. En todo caso, la forma cómplice y complaciente del sufrimiento tiende a desaparecer; ha dejado de ser indoloro, porque contiene pugnas y tensiones, reales carencias del individuo. Del sufrimiento porque si estudiantil pasa a esta clase de sufrimiento porque no que lo define como sujeto desiderativo. En segundo lugar, esta forma de acción ficticia y efectiva al mismo tiempo determina en buena medida la composición de las figuras dominantes. Ese "hondero" que lanza piedras al vacío, que mueve sus brazos como aspas, ese guerrero que tira sus flechas sobre no se sabe qué blanco, expresan arcadamente una avidez sin objeto, sólo consciente de si misma y de su raíz. En la poesía de El bondero entusiasta y de los Veinte poemas, existen dos sectores discernibles de elementos objetivos: el sector del hierro, de las cosas penetrantes y desgarradoras (arados, túneles que pertenecen al sistema del tren, espadas) y un sector más primitivo, en que las armas indígenas dan la tónica. Que se nos entienda bien: es obvio que en la fase de la poesía amorosa de Neruda estos elementos materiales representan un decorado primitivista, una especie de ropaje exotista muy en el gusto del Modernismo. Justamente porque se trata de eso: de un exotismo de lo propio, de las armas y de instrumentos que han pertenecido a una historia que se sublima líricamente, es porque posee valor representativo. Son objetos de conciencia inmediata, sin ningún ingrediente reflexivo. Imaginemos una experiencia ideal, dentro del marco de lo probable. Hé ahí un arado. Para el niño que fue Neruda, fue quizás un gran juguete deleitoso, un insecto gigantesco que se movía sobre la tierra. En su poesía, en esta primera poesía, hay sólo un uso práctico de la palabra. Nada más, en principio. Pero ya en ese simple uso se va forjando un grado ulterior de conciencia, que permitirá situar la palabra-objeto en la interacción de sus relaciones concretas. Hé aquí el poeta, luego de es. 
cribir varios libros, incluso en el mismo momento en que los escribe, que se mira a si mismo y se contempla a través de su poesia. Hay espadas, arcos, flechas, túneles, trenes. ¿Es esto un puro desván de cosas arrumbadas? ¿Dónde está el centro de su evidente coherencia? De este modo, la progresiva conciencia sobre la significación y el origen de la propia poesía surge con la práctica misma, no es pre-existente. Neruda, poeta de la Frontera, va adquiriendo conciencia de su enlace con esta zona mediante signos tan delgados y al parecer tan evasivos como estas armas, estos elementos convencionalez de sus poemas amorosos. Pue las palabras lujosas y exotistas que en ellos utiliza son también vehículos para la cons. titución de una memoria de lo colectivo. Cuando escribe:

Fui solo como un túnel. De mí huían los pájaros

y en mí la noche entraba su invasión poderosa.

Para sobrevivirme te forjé como un arma, como una flecha en mi arco, como una piedra en mi honda.

Márcame mi camino en tu arco de esperanza y soltaré en delirio mi bandada de flechas,

no sólo resultan versos sin repercusión, palabras que quedan allí, sino un secreto poder de ramificación que todavía no advierte sus verdaderas raíces. Son dos caras de lo mismo: esos rastros de no se sabe qué, esas huellas sin contenido definido se complementan, sin duda, con estos objetos que no se reconocen como rastros, que no se aprehenden como huellas. Residencia en la tierra fundirá esas dos caras. Aparecerá, entonces, el rostro integro de la tragedia. Es decir, el conjunto de sus máscaras. En tercer lugar, es indiscutible que existe una mediación social en el fenómeno de esa mujer perpetuamente ausente que nos muestra su poesía. Ya las líneas de Sexo lo advertían. Esta mujer no guarda ningún lazo con el sujeto, pero le está vedada: la ley se la prohibe. Esta otra, más cercana, pertenece a su familia: la vieja condenación del incesto la aleja irremediablemente. Por razones morales, se reprueba incluso el contacto con su propio cuerpo. Queda apenas una sola salida: la mujer-mercancía; pero también se la impide la pobreza. Deseo prohibido, condenado o reprimido, deseo de lo inalcanzable: toda la sociedad contribuye a concebir la satisfacción del apetito sexual como anti-social. Su poesía es, entonces, desde este punto de vista, un modo determinado de asimilar la sociedad, de integrarse a ella. Su deseo amoroso es re-acción en sentido propio, un duplicado de constricciones todopoderosas. En ese sujeto que 
lucha impulsivamente por dar corporeidad a sus imágenes, por dar consistencia a sus ensueños de la mujer, sería difícil no ver la angustia de un adolescente para quien las mujeres que llenan las calles son todas inaccesibles. ¿Pues qué son, a la postre, sus imágenes, sino pobres negativos, trasuntos exiguos de esos cuerpos innumerables que están alli, a la mano, y son, sin embargo, dolorosamente distantes? Inmediata e imposible, tal es la contradicción insuperable de la mujer, que el poeta experimenta $y$ vive a cada instante. $Y$ es en este momento donde el reflejo genera su rol ideológico, en cuanto tiende a apaciguar la menesterosa situación social del poeta. Es la función compensatoria que cumple el amor en esta poesía. Lo mismo que la cultura para la pequeña burguesía es un vehículo que le permite igualatse con las clases superiores, el amor es también, aunque no se lo crea, un mecanismo de uniformación social que opera en el marco de muchas superestructuras. Ante el amor se evaporan las diferencias de clase: ino es inhumano pensar otra cosa? "Sólo el amor es fecundo" decía, con frase robada, Alessandri, el líder nacional de las capas medias. Se refería, por supuesto, a una in. explicable fecundidad social. La biología nada sabe de la organización que se dan los hombres. En la esfera del instinto, en la esfera de la carne, en la esfera del sentimiento, todos somos igualmente ricos, igualmente nobles. Estas bellas consolaciones ideológicas encuentran su confirmación en medio de un panorama natural, donde las fuerzas sociales han sido cuidadosamente borradas. Bosques, mar, vientos, estaciones del año: la sociedad es un mal extirpado en los Veinte poemas. ¿Pero qué hace, en el fondo, esta naturaleza sino tapar, cubrir, enterrar desesperadamente las evidencias implacables que la sociedad impone? En el Poema 9 escribe Neruda:

Pálido y amarrado a mi agua devorante, cruzo en el agrio olor del clima descubierto, aún vestido de gris y sonidos amargos y una cimera triste de abandonada espuma.

Al parecer, en este poema el deseo y el acto eróticos han sido tratados oníricamente. De ahí, entonces, que la significación vacilante de ciertos elementos se haga compleja, más penetratante de comprensión. El poeta diseña su propia identidad. Esta "indumentaria estrafalaria"13 con que se nos presenta es bien reveladora. Como algunos personajes de Picasso - como sus famosos Arlequines, por ejemplo- este sujeto transparenta

13 Magdalena Petit: "Pablo Neruda (analizado en una de sus poesías)". Aterea, núm. 99, julio de 1933, p. 102. 
su ánimo en su ropa. No hay discontinuidad entre sicología y vestimenta: el atuendo es simplemente ánimo exteriorizado $y$, ¿por qué no?, ánimo socialmente producido. En efecto, es visible la sensibilidad, la atención casi sistemática que el poeta presta a las distintas formas de vestir y a sus correspondientes circunstancias sociales. En Diurno doliente escribirá más tarde, impregnando todo el traje de vehemencia interior:

Porque la ventana que el mediodía vacío atraviesa tiene un día cualquiera mayor aire en sus alas, el frenesí hincha el traje y el sueño al sombrero, una abeja extremada arde sin tregua.

En Residencic en la tierra habrá un abanico que se extiende desde el vestido de novia hasta el "delirante luto". Este derrama, en su color sombrío, ceremonias de duelo, velorios, hechos funerales de esa poesía. En el centro de esos extremos, está el "traje nuevo" que viste Alberto Rojas Jiménez difunto y ese "traje sin luz" que se pone de preferencia el poeta. Habría que comparar esta sicología material de la ropa, vibrante de asociaciones y descubrimientos, con la poetización a que se entrega Vallejo, quien siente sobrevivir a su familia en las partes, en los miembros de su cuerpo y que toda la sociedad lo penetra en su camisa, en sus zapatos, en sus pantalones. iIncreíble coincidencia de dos grandes hispanoamericanos!

Recordemos las tres necesidades básicas del ser humano determinadas ya en la Repuiblica de Platón: la alimentación (tropbé), la vivienda (oikésis) y el vestido (esthés). ${ }^{14}$ Apenas provisto de la primera y huérfano de propiedad sobre la segunda, el pequeño burgués exacerba su atención a la tercera. Sociológicamente - se lo ha dicho tantas veceslas capas medias creen definir su status social en su modo de vestir, por la calidad o la apariencia de su ropa. La existencia juvenil de Neruda está llena de la constante preocupación, de la humillante necesidad del vestuario. Tal es su poesía, la de un ser que habita en medio de la naturaleza y que hace de toda ella su gran vivienda imaginaria, la de un ser que omite en ella una alimentación que siempre ha sido considerada subpoética, y que de pronto nos deja una insignificante señal de su preca. riedad social: el testimonio de su traje. Gris es aquí el color de la pobreza, un color opaco y desvaído. Lo decimos sin ambages: si hay algo que representa la poesía de los Veinte poemas, si hay algo que determinó una lectura tan extendida en los países del Continente, no es otra cosa que

74 II, $369 \mathrm{~d}$. 
el eros de la pobreza, un amor a la medida de la clase media. Pero, mal entendidos aparte, Daniel de la Vega y otros poetas menores han buscado expresar lo mismo. Fue a Neruda, sin embargo, a quien cupo alcanzar la plenitud del sentimiento que esas condiciones posibilitaban, una más alta jerarquía de belleza. Materialista en su sentido profundo, en cuanto es fiel a la esencia complementaria y totalizadora del amor, este sentimiento idealiza la situación de la clase media a que pertenece el sujeto. Sin disputa, la elaboración y la boga de estos poemas se producen en un momento de ascenso de esas capas en las sociedades del Continente. Culturalmente mimetizadas con las clases dominantes, participando del poder en distinto grado según sea el pais, estas capas tratan de crear mitos alentadores sobre su situación de clase. La fuerza no apagada, duradera, de estos poemas verifica su validez, su significación histórica. Pues si el Modernismo fue un movimiento de $\mathrm{l}_{a}$ clase media que a fines de siglo todavía añoraba, con Darío, la situación del poeta en las cortes coloniales, su condición de artista palaciego, poco a poco fue afirmándose una actitud más positiva, más decidida, que corría a parejas con el avance incontenible de ese sector social. Neruda representa quizás, con esta juvenil poesía, la culminación de aquel proceso. Antes de él las formula. ciones fueron débiles y marcadamente ideológicas y necesitaron recurrir a los valores vigentes en otras superestructuras, especialmente a los religiosos. Es lo que, para el caso de Neruda, veíamos ya en un poema contemporáneo a la génesis de Crespusculario y que puede observarse también en el desteñido misticismo de Amado Nervo, inspirado en fuentes católicas o, con mayor densidad lírica, en Angel Cruchaga. La poesía de Neruda, en cambio, saca sus fuerzas de sí misma y forja sus mitos con casi una completa autonomía imaginativa. Incluso cuando bordea peligrosamente la ambigüedad del tener, el conflicto de la posesión en su sentido amoroso y económico a la vez:

Aquí te amo y en vano te oculta el horizonte.

Te estoy mirando aún entre estas frías cosas.

A veces van mis besos en esos barcos graves, que corren por el mar hacia donde no llegan.

Ya me veo olvidado como estas viejas anclas.

Son más tristes los muelles cuando atraca la tarde.

Se fatiga mi vida inútilmente hambrienta. Amo lo que no tengo. Estâs thit tan distante.

Mi hastío forcejea con los lentos crepúsculos.

Pero la noche llega y comienza a cantarme.

La luna hace girar su rodaje de sueño. 
Me miran con tus ojos las estrellas más grandes. $\mathrm{Y}$ como yo te amo, los pinos en el viento, quieren cantar tu nombre con sus hojas de alambre.

La poesía exhibe tal capacidad de transfiguración, el espectáculo de la naturaleza tiene tal fuerza compensatoria que se impone a estas incrustaciones de conciencia dolorosa. Ocurre aquí, con más poder y eficacia, lo que en las novelas chilenas del 38 sucederá en menor medida y sólo de manera provisional. En Daniel Belmar, en Nicomedes Guzmán o en Rubén Azócar la contemplación de las noches estrelladas de la pampa, la frescura del mar o el ímpetu del viento serán a menudo valores sociales disfrazados en medio de la dominante miseria de sus personajes.

La naturaleza es, pues, la primera vertiente de la compensación. Hay una segunda, que se inserta en el campo mismo de la historia:

aún vestido de gris $\mathrm{y}$ sonidos amargos

y una cimera triste de abandonada espuma.

Es difícil resistir la identidad social. El poeta crea, por lo tanto, hurgando en una intimidad oniricamente estimulada, una imagen de otro tiempo, que desvía la atención del presente prosaico. Un penacho emerge, como resto de una antigua armadura. Este dato bizarro amortigua las evidencias actuales de su situación, la diluyen en un pasado débilmente presentido. Así, actual y anacrónico, cotidiano y armado, gris y pictórico, el sujeto revela y oculta simultáneamente su ser de clase. Sugiere y desvanece un reconocimiento insoportable. Súmense las constataciones: aquellos rastros indefinidos, esos objetos (instrumentos y armas) que eran reliquias estetizadas de una imponente gesta histórica, esta hibridez temporal que el personaje lírico ahora nos exhibe; sumadas, tenemos un terreno histórico que el poeta asedia, presionando suavemente, sin comprender todavía toda su proyección. La voz de la autoconciencia colectiva es apenas una musitación:

Escuchas otras voces en $\mathrm{mi}$ voz dolorida.

Llanto de viejas bocas, sangre de viejas súplicas.

Delimitado el suelo de los hechos, estatuido un nivel primario de conciencia, construido su mundo amoroso con lo que fueron materiales de la guerra, esta poesía suprime el estado actual de la sociedad en beneficio de una experiencia, en curso de constitución, donde no asoma aún la 
estratigrafía social. Lo que el aprismo realizaba en el Perú por esos mismos años, levantar el espectro indígena como un ideal de las capas medias, se realiza acá también, no en el plano de la ideología política, sino de la imaginación artística. Y una observación más, que comprueba como los detalles se subordinan y se incorporan a las concepciones poéticas dominantes. La obsesión de los sastres en Residencia en la tierra (: "Converso con los sastres en sus nidos") halla aquí su primer germen, en este enlace, fácil de descubrir, con la visión de la ropa y de retazos materiales de la Conquista. Demonios del tiempo por las agujas maléficas con que cosen, los sastres son también dioses dispensadores del vestido y destructores de la desnudez indígena. ${ }^{15}$ Todo está de tal modo compenetrado que es casi indiscernible al análisis. Residencia en la tierra erigirá en valor absoluto la desnudez de la piel, no sólo como repudio a la explotación del consumo vestimentario, sino, más profundamente, como reactualización de un paradigma de hombre natural identificable con las víctimas de la Conquista. De este modo, el poeta llega a una indiscutible experiencia histórica por una vía equívoca. Es éste el camino en la constitución de un valor líricamente fundado: acosado por las necesidades cotidianas de abrigo, recusando por impotencia el dispendioso lujo vestimentario, un sujeto elige y se construye un mito sustitutivo. Tal es su parábola de clase, el resultado elusivo a que accede. La desnudez aborigen es, entonces, primero, compensación de reales dificultades o carencias, y luego instauración de un contenido olvidado que se opone a un tiránico sistema de alienación. Mixtificada en su origen, la experiencia genera su verdad en contra de las falsedades y de las limitaciones de la organización social.

No es excepcional este caso en el funcionamiento de las ideologías artísticas. A menudo, en la novela o en la poesía, se encuentran valores humanos permanentes a contrapelo, por evasión de formas históricas actuales, como rescate de segmentos ideológicos correspondientes a formaciones socio-económicas superadas o por el choque de intereses diferen. ciados de clase. Se conoce, en este contexto, la crítica romántica anticapitalista, en la cual ha insistido Georg Lukacs en sus escritos. Es fácil advertir, en lo que respecta a Neruda, el mismo procedimiento oblicuo, en que virtualidades positivas se engendran a partir del distorsionamiento de su situación de clase.

15 En otro ensayo he hecho notar la importancia que adquieren, en los primeros años de la Conquista, los oficios de sastre, bonetero y calcetero y la ramificación creciente de sus labores. La satisfacción de una necesidad se convierte, para los españoles, en simbolo social y cultural. (Cf. "El otro nuevo mundo". En: Homenaje a Ercilla. Concepción, Universidad de Concepción, 1970). 
Naturaleza y protohistoria, aunque direcciones de la compensación, no son zonas socialmente neutrales. Este poeta que se refugia en los bosques y que escucha el canto del viento se hace un conocedor extremado de esa vida. Advierte, entonces, en el juego de sus ciclos, en el movimiento y en la renovación de la naturaleza, su secreto poder germinativo. No sólo hay belleza en ese ámbito, decorado, escenario: hay también fuerzas que se adivinan, impulsos creadores que visualizan una especie de utopía. Deseada y buscada en cuanto no-sociedad, experimentada como anti-sociedad, esta naturaleza entrega al poeta signos, cifras que él interpreta como prometedoras perspectivas sociales. Tal es la ventaja de la poesía lírica, que puede ver en el esplendor de un árbol o en el brillo de una estrella esperanzas a la medida del hombre. Era la actitud de Darío, cuando se extasiaba ante la comunidad armoniosa que vislumbraba en el vuelo colectivo de las aves.

Si la naturaleza opera por desplazamiento, por sustitución de valores sociales acaso, la protohistoria esbozada en esta poesía lo hace por totalización. El núcleo originario que se entrevé absorbe los desgarramientos y escisiones de la experiencia social. Sin embargo, la sociedad no se evapora. Surgido quizás por imperativo de olvido, este pasado al que co. mienza a orientarse la poesía busca tegenerar la sociedad, ponerla en marcha de nuevo. Lejos de configurar una ciega utopía, origina más bien una fuente de nostalgia creadora, donde los minúsculos conatos de his. toria se impregnan de energía colectiva. En esto consiste el carácter positivo de esta clase de compensación: en coger la sociedad de raíz, en su raíz cronológica. La huida de clase contiene, por lo tanto, un sentido enriquecedor. Es la huida hacia el arraigo. La clase que busca escapar a su ser limitado y precario se experimenta en ese período de la historia participando en el movimiento general, en un todo social que se crea $y$ se funda gracias a su propia actividad. Esos rastros, esas armas, esa ves. timenta subyacente al traje de todos los días da profundidad a una clase, la vivifica, la expande. Es éste el gran fenómeno de trasmutación social que el sentimiento del amor ha posibilitado.

Recapitulo este camino simple y verificable. Un joven experimenta el amor como algo socialmente vedado, siente en sí el deseo insatisfecho, ve allí el origen de la insatisfacción de todos sus deseos: la autoconciencia ha nacido, instintiva, individual, social, todo al mismo tiempo. "Amo lo que no tengo": identificado, retratado en su ser menesteroso, el deseo se revela como el estrato primario de esta conciencia que empieza a reconocer el mundo. Apetencia de realidad, esto es, de realización, el deseo amoroso lo es también en el orden social. De ahí el ambiguo pasatismo 
de esta poesía nerudiana, que busca englobar desde abajo la sociedad y su historia. Cogida en su posibilidad, en sus virtualidades, en su deseo en fin, la sociedad es negada y afirmada en un mismo acto poético. El sujeto de este acto ya no es más el adolescente inmortal de Pantheos, con sus "manos blancas" y de "cabeza triste"; tampoco el "espíritu intocado" de Oración: aunque irreal, aunque fantasmagórica, la historia ha depositado una huella de tiempo en este personaje, en su emocionalidad, en la forma de su ropaje. No es niño ni estudiante. Miembro indefinible de una clase indefinida, es sólo un fugitivo de su situación, de su nada social: "Amigos vueltos a la zona de la sombra; mujeres que construyeron besos y sueños distantes; ahora, en esta hora de examen, siento que, a la vez, sólo fuisteis variaciones que creó $\mathrm{mi}$ sed, mi deseo infinito, que yo fui creado por vosotros en vuestra fuga hacia la noche."1s

JAIME CONCha

Universidad de Concepción, Chile

16 Claridad, 21 de julio de 1923. 
